\title{
A Study on Soldier Cap Disorder in Penaeus vannamei from Culture Ponds of Andhra Pradesh, India
}

\author{
Suresh Kummari ${ }^{1^{*}}$, Neeraja Tambireddy ${ }^{2}$, B. Madhusudhan Rao ${ }^{3}$, Srinu Rathlavath ${ }^{4}$, \\ Satyanarayana Boda ${ }^{5}$ and Lavanya Chethurajupally ${ }^{2}$
}

${ }^{I}$ Department of Aquatic Animal Health Management, College of Fishery Science, P.V. Narsimha Rao Telangana Veterinary University, Pebbair-509104, Telangana, India

${ }^{2}$ Department of Aquatic Animal Health Management, College of Fishery Science, Sri

Venkateswara Veterinary University, Muthukur-524344, Andhra Pradesh, India

${ }^{3}$ Department of Aquatic Animal Health Management, Central Institute of Fisheries Education, Mumbai-400061, India

${ }^{4}$ Department of Fish Processing Technology, College of Fishery Science, P.V. Narsimha Rao

Telangana Veterinary University, Pebbair- 509104, Telangana, India

${ }^{5}$ Department of fishery economics and statistics, Faculty of Fishery sciences, West Bengal

University of Animal and Fishery Sciences, Kolkata-700094, India

*Corresponding author

\section{A B S T R A C T}

Pacific white shrimp, Penaeus vannamei is the most extensively farmed crustacean species in the world as well India.In India, Andhra Pradesh state is occupying first place in culture production of vannamei shrimp. In recent years, P. vannamei faming in Andhra Pradesh is

\section{Keywords}

Penaeus vannamei, shrimp farming, soldier cap disorder, Andhra Pradesh, India

\section{Article Info}

Accepted:

28 March 2018

Available Online:

10 April 2018 being encountered with multiple diseases such as running mortality syndrome (RMS), white spot syndrome virus (WSSV), white faeces/ white gut syndrome and severe retarded growth due a microsporedian, Enterocytozoon hepatopenaei (EHP) infection causing catastrophic influence on economy. Besides these diseases, cultured P. vannamei in Andhra Pradesh is being affected with soldier cap disorder with a clinical symptom of carapace folding out from the gill region at both sides, leading to moulting problem and poor growth rate in shrimp. In this connection, a study was conducted for a period of eight months from March 2017 to October 2017 in vannamei culture ponds of Nellore, Prakasam, Krishna and West Godavari districts of Andhra Pradesh state to analyze the possible causes of soldier cap in vannamei with respect to various pond management practices. The prevalence of soldier cap in P. vannamei noticed was $20 \%, 40 \%, 30 \%$ and $30 \%$ in Nellore, Prakasam, Krishna and West Godavari districts respectively. A co-relation was observed between stocking density, pond water quality parameters and soldier cap disorder. This study represents the first record on the emergence of soldier cap disorder in P. vannamei. 


\section{Introduction}

Shrimp culture in India is growing at the exponential phase with remarkable growth both in terms of culture area and export value (Rajendran et al., 2016). Having a coast line of $8118 \mathrm{~km}$ along with 3.5 million ha of estuaries and 3.9 million ha of backwaters makes India much suitable for shrimp aquaculture. About 1.2 million hectares of brackish water area in the country is under shrimp culture (Sedhuraman et al., 2014). Andhra Pradesh state is flourished with immense source of brackish water area of 1.75 lakh hectares, which is ideal for cultivation of shrimp and other brackish water species. Currently, Penaeus vannamei (Boone, 1931) and Penaeus monodon (Fabricius, 1798) are the two species of shrimps ruling the shrimp culture and exports throughout the world contributing $80 \%$ of the total shrimp production (FAO, 2009). At present, $P$. vannamei is a popular cultured species in India and its culture was initially taken up by Andhra Pradesh state during 2009 (CAA, 2010). After the devastation of $P$. monodon culture with white spot syndrome virus (WSSV), $P$. vannamei came as lucrative financial returning species in Indian aquaculture industry (Sedhuraman et al., 2014). However, in recent years $P$. Vannamei faming is facing hardships with diseases of various aetiological agents as well as morbidity associated with poor management practices causing catastrophic influence on the farmer's economy (Rajendran et al., 2016; Santhosh Kumar et al., 2016; Suresh et al., 2018b).

Diseases are the outcome of imbalance between three systems viz., environment, host and pathogen (Snieszko, 1974). The impact of disease is a combination of several factors such as mass mortality of shrimp, reduction in feed acceptance or morbidity and these conditions ensures the health status of the cultured animal (CAA, 2010). Modernization of culture techniques such as high stocking densities and use of compound pelleted feeds in order to achieve higher production creates an imbalance in aquatic environment leading to diseases (Alavandi et al., 1995). Availability of good quality post larvae, construction of Effluent Treatment Plant (ETP) and implementation of better management practices in various aspects of shrimp culture are most important activities to manage emerging diseases. The production losses in $P$. vannamei are mainly due to multiple disease conditions such as WSSV, running mortality syndrome (RMS), white faeces/ white gut syndrome and retarded growth due to a microsporidian parasite, Enterocytozoon hepatopenaei (EHP) infection (Suresh et al., 2018b; Rajendran et al., 2016; Santhoshkumar et al., 2016; Mastan, 2015; Ahmad et al., 2017; Tourtip et al., 2009). Recently, shrimp farms in Andhra Pradesh are being affected with 'soldier cap disorder' at cephalothorasic region leading to production losses in shrimp farming. The present study was conducted to analyze causes of soldier cap disorder in shrimp culture ponds of different districts in Andhra Pradesh, India with respect to various pond management practices.

\section{Materials and Methods}

\section{Study area}

Survey was done in four districts of Andhra Pradesh viz., Nellore, Prakasam, Krishna and West Godavari. Selection of these districts was done as they contribute substantially for shrimp production of the state (Fig. 1).

A survey was conducted in 52 farms of $P$. vannamei in Nellore, Prakasam, Krishna, and West Godavari districts of Andhra Pradesh, India. Survey was carried out with the help of questionnaire to conduct the passive 
surveillance for soldier cap disorder in $P$. vannamei. Apre-tested questionnaire involving measurements like pond area, stocking density, days of culture (DOC), harvested biomass, feed conversion ratio (FCR), average body weight, total feed consumption, seed survival rate, count, information of shrimp culture practices, production, disease history, availability of facilities and improvement of bio-security measures was noted.

The survey was carried out for a period of eight months from March 2017 to October 2017.Along with the survey, water quality parameters were also analyzed.

\section{Statistical analysis}

Data was analyzed using unpaired t- test with the help of SPSS 22 (License), to know whether there is significant difference in the water quality parameters between normal and soldier cap disorder ponds.

\section{Results and Discussion}

Survey was conducted in the shrimp culture areas of four districts where shrimps were earlier reported to shown the soldier cap disorder. A total of 52 farms surveyed for the soldier cap disorder in $P$. vannamei involving 16 farms in Nellore, 13 farms in Prakasam, 10 farms in Krishna and 13 farms in West Godavari have shown the prevalence of $20 \%$, $40 \%, 30 \%$ and $30 \%$ respectively (Fig. 3J) with a clinical symptom of carapace folding out from the gill region of the shrimp (Fig. 2). However, these observations were found where the water quality parameters were beyond the normal range (Table 1). FCR was found to be high in soldier cap disorder farms, on the other hand survival rates were found to be significantly low $(\mathrm{p}<0.05)$ as mentioned in table 2. A co-relation between stocking density, water quality parameters and soldier cap disorder were observed. Soldier cap disorder was observed after 50 days of culture period. It was noticed that compared to past culture practices, current mode of culture in the mentioned four districts is highly intensive, however with limited adaptation of good management practices.

From table 1, it can be clearly observed that there is a significant difference $(\mathrm{P}<0.05)$ in temperature, dissolved oxygen, alkalinity and hardness values between soldier cap affected and normal ponds. However, no significant difference $(\mathrm{P}>0.05)$ in salinity, $\mathrm{pH}$, and ammonia values were observed.

During the last few decades, shrimp culture has emerged as one of the major income generated industry in tropical and subtropical areas of the world, especially for coastal populations (Adger, 1998).In India, commercial shrimp farming started in mid 1980s and now became the third biggest shrimp aquaculture producer in the world (FAO, 2016).

Moreover, the impact of diseases due to virus, bacteria, parasites and environmental conditions plays a significant role in shrimp production. More recently shrimp culture in Andhra Pradesh is being affected with soldier cap disorder in $P$. vannamei, affecting shrimp production and causing production losses to the farmers. Affected population exhibited elevated FCR, growth retardation, low survival rate and variable sizes of individual at the harvest.

To identify the main causes of soldier cap disorder, survey was focused on the water quality parameters, FCR, survival rate and biomass of the sampled ponds. Most of the diseases in shrimp farming are exclusively caused by infectious agents (viruses, bacteria, protozoan and fungal), whereas in support to them, non-infectious diseases also emerged as another health issue (Suresh et al., 2018a). 
Table.1 Average values of water quality parameters in soldier cap disorder affected and normal shrimp ponds

\begin{tabular}{|c|c|c|c|c|c|}
\hline \multirow[t]{2}{*}{ Parameter } & \multicolumn{3}{|c|}{ Mean \pm SD } & \multirow[t]{2}{*}{$t_{\text {cal }}$} & \multirow[t]{2}{*}{$\mathbf{P}$} \\
\hline & $\begin{array}{l}\text { Soldier cap } \\
\text { affected ponds }\end{array}$ & \multicolumn{2}{|c|}{ Normal ponds } & & \\
\hline Temperature & $31.86 \pm 1.49$ & \multicolumn{2}{|c|}{$30.80 \pm 1.06$} & $3.035923^{* *}$ & 0.0033 \\
\hline Dissolved oxygen & $4.86 \pm 0.50$ & \multicolumn{2}{|c|}{$6.30 \pm 0.75$} & $-9.72896^{* *}$ & 0.0000 \\
\hline \begin{tabular}{|l|} 
Salinity \\
\end{tabular} & $17.98 \pm 4.60$ & \multicolumn{2}{|c|}{$15.77 \pm 4.23$} & 1.93003 & 0.0575 \\
\hline Alkalinity & $153.15 \pm 24.01$ & \multicolumn{2}{|c|}{$110.55 \pm 24.50$} & $6.93401^{* *}$ & 0.0000 \\
\hline \begin{tabular}{|l|} 
Hardness(Calcium) \\
\end{tabular} & $120.47 \pm 22.34$ & \multicolumn{2}{|c|}{$93.45 \pm 32.09$} & $4.153015^{* *}$ & 0.0000 \\
\hline $\mathrm{p}^{\mathrm{H}}$ & $8.04 \pm 0.41$ & \multicolumn{2}{|c|}{$7.88 \pm 0.32$} & 1.645714 & 0.1041 \\
\hline Ammonia & \multicolumn{3}{|l|}{$0.10 \pm 0.08$} & 0.816862 & 0.4167 \\
\hline \multicolumn{6}{|l|}{$\begin{array}{l}\mathrm{t}_{(72)}=1.993464 \\
* \text { significant at } 0.05 \text { level }\end{array}$} \\
\hline \multicolumn{6}{|c|}{ Table.2 Comparision of FCR and Survival rate in the normaland soldier cap affecte } \\
\hline Parameter & \multicolumn{2}{|c|}{ Normal ponds } & \multicolumn{3}{|c|}{ Soldier cap affected ponds } \\
\hline FCR & \multicolumn{2}{|c|}{1.28} & \multicolumn{3}{|c|}{1.65} \\
\hline Survival Ra & \multicolumn{2}{|l|}{$71 \%$} & \multicolumn{3}{|l|}{$52.5 \%$} \\
\hline
\end{tabular}

Fig.1 Study areas of P. vannamei culture in Andhra Pradesh, India

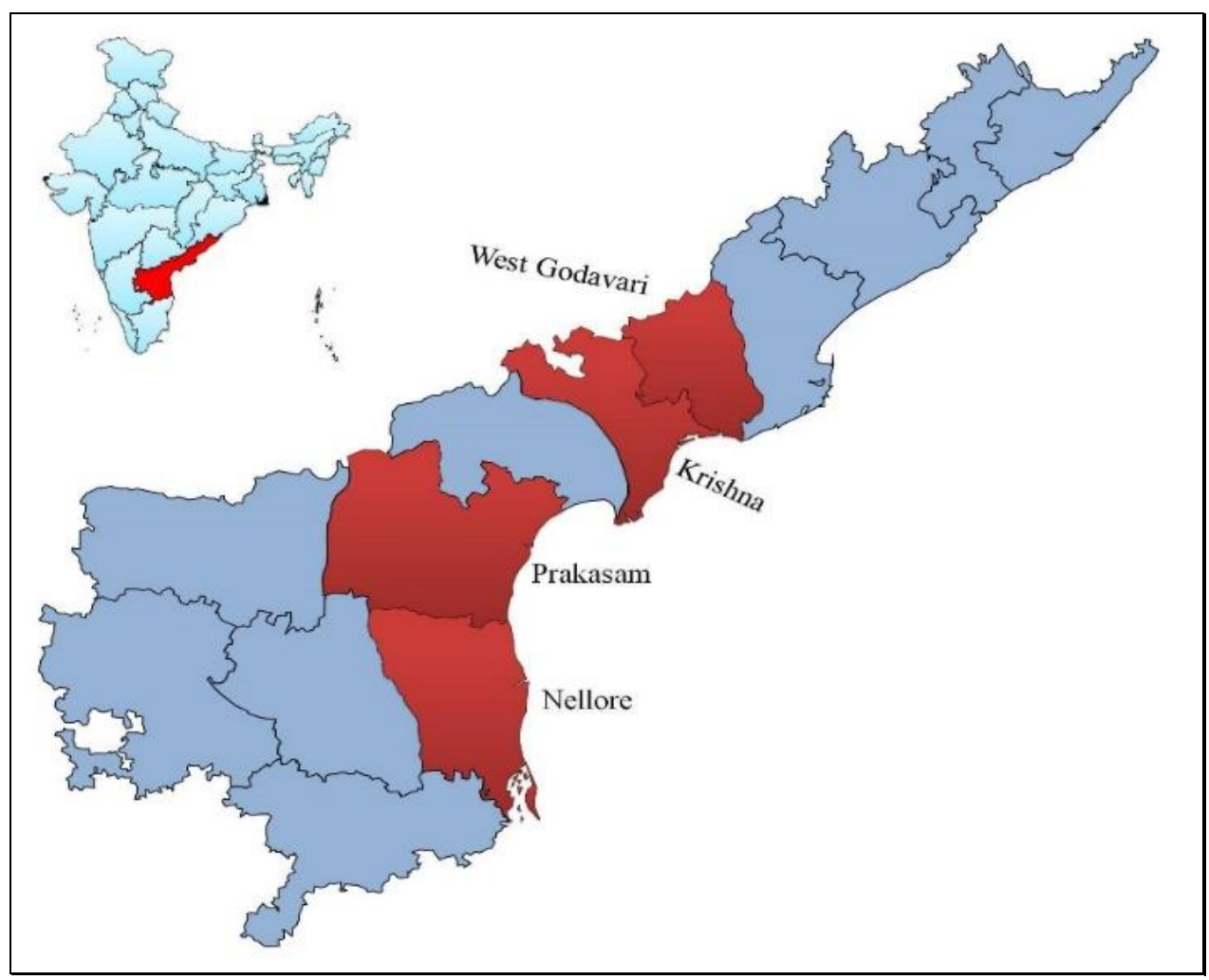


Fig.2 The soldier cap disorder (arrow) in cephalothorax (gill) region of $P$. vannamei

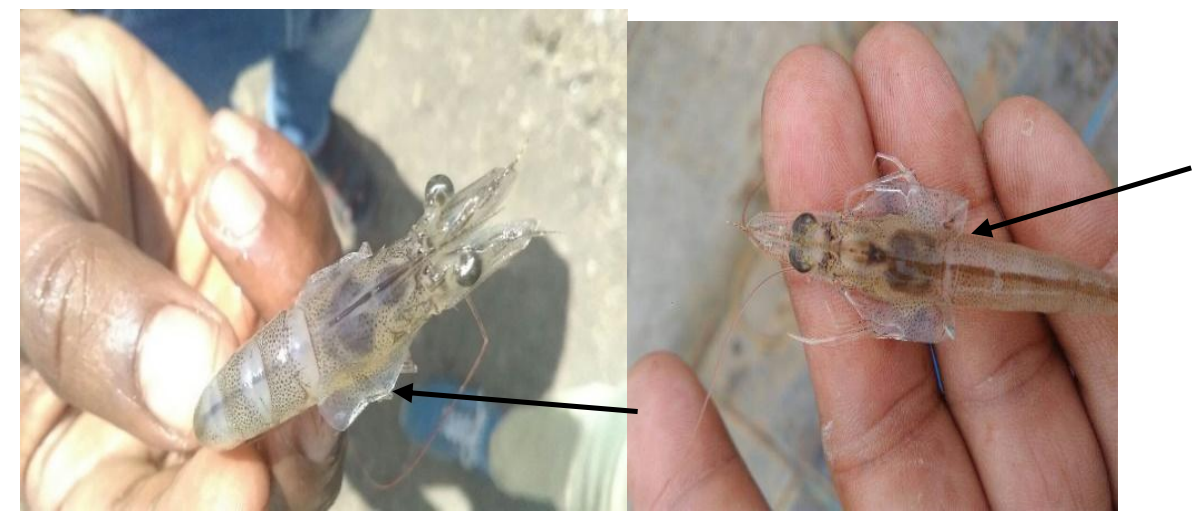

Fig.3 Farm level observations during the survey. Water quality difference between soldier cap affected and normal shrimp cultured ponds. A. Temperature, B. Dissolved oxygen, C. Salinity,

D. Alkalinity, E. Hardness, F. pH, G. Ammonia, H. FCR, I. Survival rate, J. District-wise prevalence of soldier cap disorder.

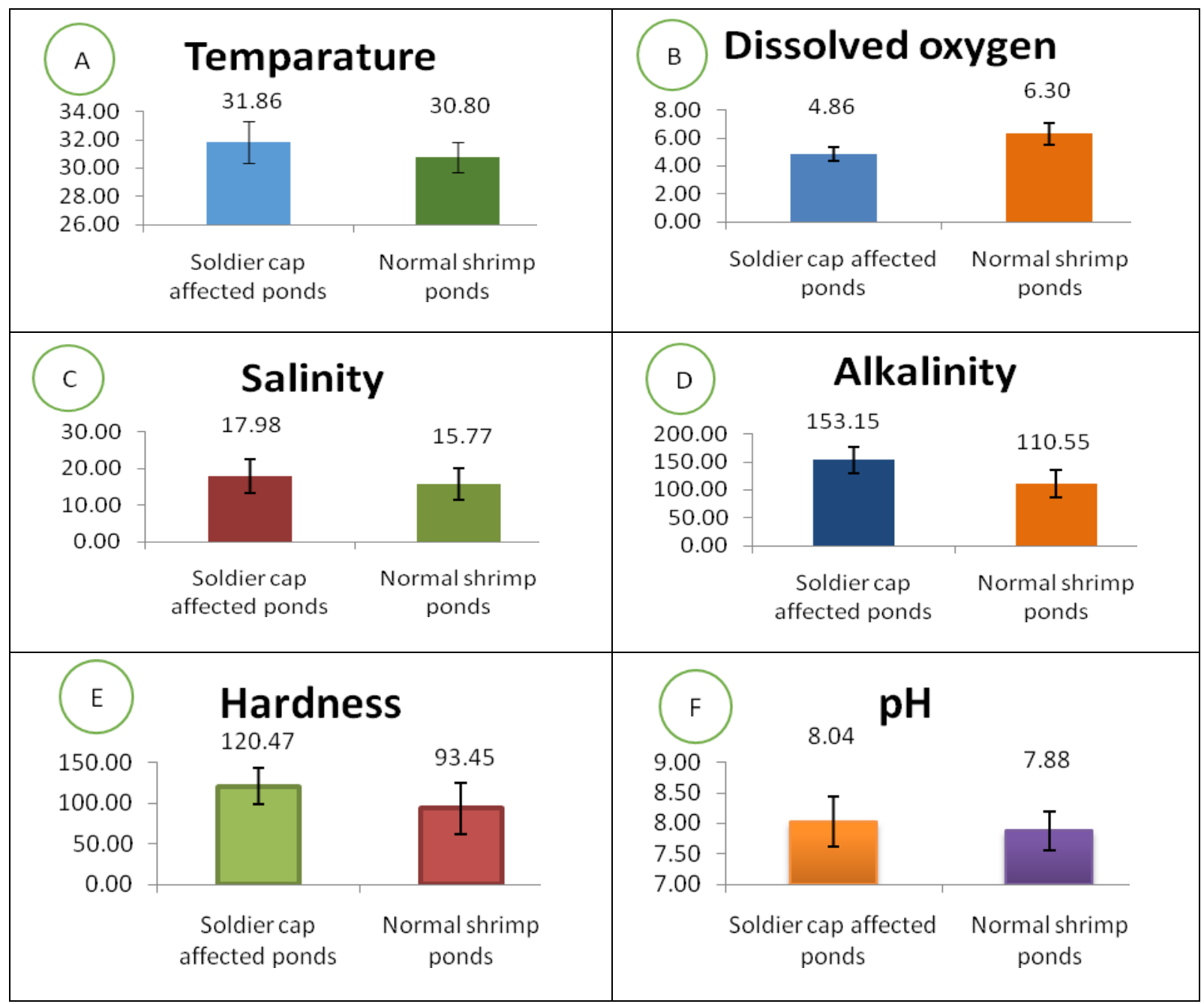




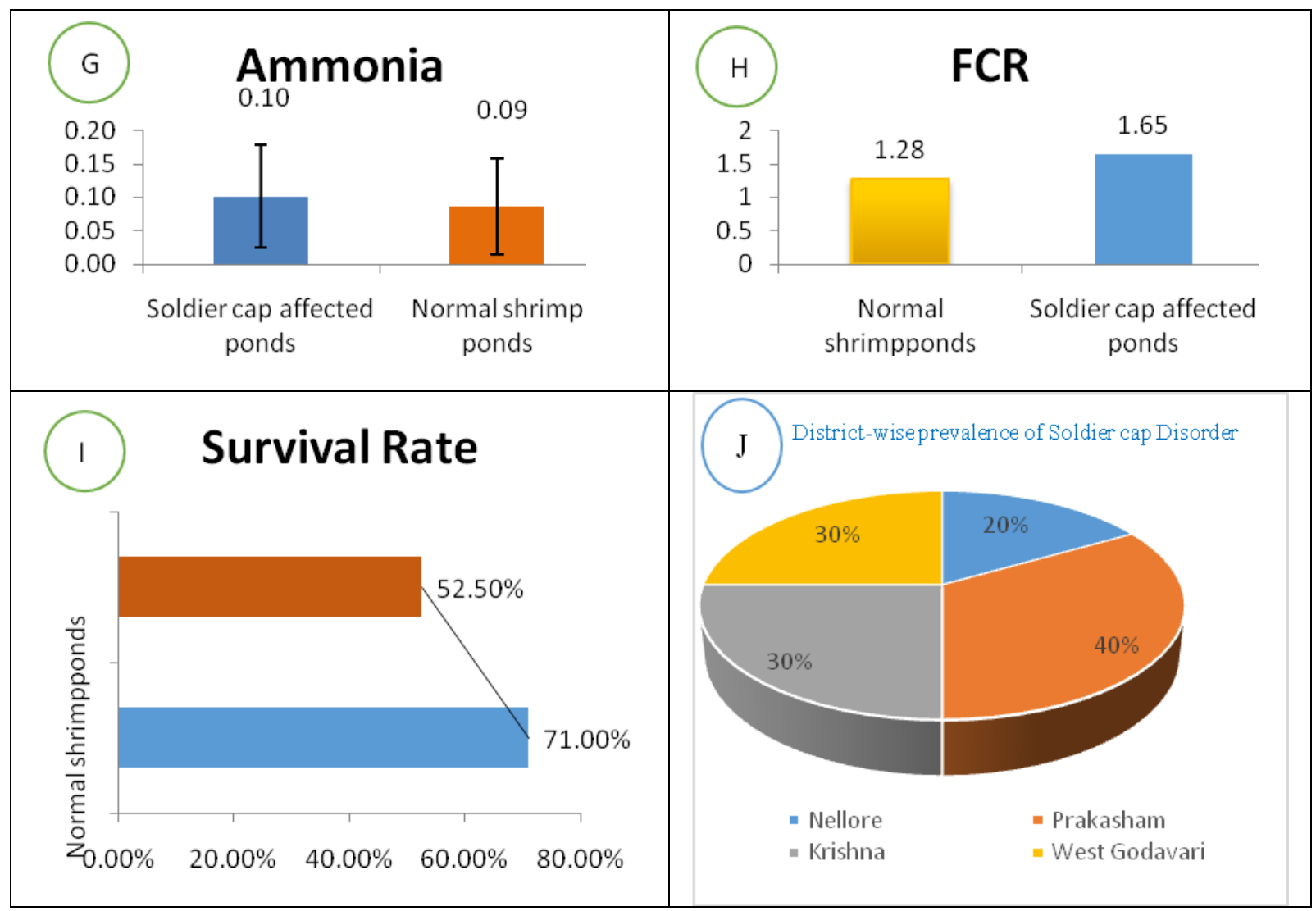

Stocking density, quality of seed, carrying capacity of the pond and good feeding practices are the crucial areas where a successful farmer has to focus (Araneda et al., 2008; Babu et al., 2014; Karuppasamy and Mathivanan, 2013; Margabandu and Ramamurthy, 2015). As per the guidelines of Coastal Aquaculture Authority (CAA), stocking density of seed must be 60 pieces per square meter. During our survey, it was observed that farmers are stocking seed with their previous knowledge by considering season. Medium to high stocking densities of $40-50 / \mathrm{m}^{2}, \quad 60 / \mathrm{m}^{2}, \quad 70 / \mathrm{m}^{2}, \quad 100 / \mathrm{m}^{2}$ and $120 / \mathrm{m}^{2}$ were recorded in most of the farms, but soldier cap disorder was mainly observed in farms with high stocking densities. Focus on high stocking densities mainly due to modernization of culture techniques and use of compound pelleted feeds in order to achieve higher production creates an imbalance in aquatic environment leading to diseases (Alavandi et al., 1995). Further,
Araneda et al., (2008) and Babu et al., (2014) has shown inverse relation between growth of shrimp and stocking density. This clearly indicates that high stocking densities will alters the physiological conditions in shrimp, leading to the growth retardation, disease vulnerability and also affects the FCR. Maximum farms observed for soldier cap disorder in the present study showed the high FCR of 1.64 which led to considerable raise in the operational cost and days of culture. Most of the farmers adopted partial harvesting when they observed slow growth after they attain certain marketable size (Babu et al., 2014). In the present survey, $60 \%$ of the farmers followed partial harvesting after 70 days of culture where soldier cap disorder was found. Reports describe that enthusiasm of shrimp farmers in high stocking densities, use of chemicals and other unnecessary practices are mainly responsible for emergence of new diseases or increased pathogenicity in existing diseases (Murray and Peeler, 2005). 
Water quality management in aquaculture is a dynamic subject and the quality of aquatic environment is the key for obtaining best results in aquaculture. A clear-cut understanding in maintenance of nutrients and other optimum culture conditions including temperature, salinity, $\mathrm{pH}$, alkalinity, hardness, turbidity and the equilibrium between nitrogen, oxygen, organic carbon and phosphorus along with several others are utmost concern for healthy growth of shrimps (Boyd, 2003). In agreement to Boyd (2003), in the present study the water quality parameters like temperature, DO, alkalinity and calcium hardness were deviating from the normal range in the soldier cap affected shrimp ponds (Fig. 3). Shrimps are sensitive invertebrates whose survival and growth is extremely influenced by culture environment. They cannot tolerate severe fluctuations in physio-chemical parameters of water and tends to decrease its capacity to support the life leading to low survival rate in cultured biomass. Several diseases appear due to poor environmental factors such as bad hygienic conditions, inadequate water quality, low DO levels and improper feeding practices. Temperature and $\mathrm{p}^{\mathrm{H}}$ are the important water parameters for good metabolism and growth of shrimp and optimal temperature range for shrimp culture is between $24-32^{\circ} \mathrm{C}$ (Babu et al., 2014; Mude and Ravuru, 2015; Wyban et al., 1995). Most of the shrimp ponds with soldier cap were noticed to have a water temperature range of equal and above $32^{\circ} \mathrm{C}$. However, some ponds in surveyed areas temperature have reached even up to $34^{0} \mathrm{C}$. Among the 52 farms located in four districts, the prevalence of soldier cap disorder in affected ponds of Nellore, Prakasam, Krishna and West Godavari districts was 20\%, 40\%, $30 \%$, and $30 \%$ respectively (Fig. 3). Dissolved oxygen was significantly low in soldier cap affected ponds compared with normal shrimp ponds. Maintenance of reservoir pond and effluent treatment system is the essential element in shrimp farming. Small farmers are unable to maintain reservoir pond as they have very limited land for culture itself. Most of the farms do not maintain effluent treatment system. Reluctance in adoption of effluent treatment system, will contaminate the environment by release of effluents containing pathogen, chemicals directly into environment. This practice has severe long term effects on future shrimp culture, because many of the pathogens can survive in soil for a long period in environment.

Availability of quality seed in required number is the main drawback in the shrimp industry that will determine health status of animal. Seed supply is the prime issue for farmers, most of them is receiving PL of stages 7-8 instead of PL 12-15. During our study, the farmers have expressed that hatcheries are supplying seed produced from local brooders which yields low quality seed. The optimum age of PL12 and above is much capable to tolerate field conditions (Kumaran et al., 2017). In the present survey it was observed that most of the hatcheries are supplying PL of age 7-10 by the name of PL 12- 15. According to farmers, availability of healthy seed is the main constraint for obtaining the maximum outcome. Similar feedback was given by the farmers from the present study areas of shrimp farms.

Out of 52 farms surveyed, 15 farms were below 5 acres of shrimp culture and they did not follow any best management practices (BMPs) during the culture but applied prestocking management principles partially, also applying commercial feeds, application of probiotics and liming materials (every week) and there was no water exchange during the culture period, 18 farms were between 5-20 acres area and following same methods as above farmers, remaining 19 farms were having more than 30 acres and 
most of them following the pre-stocking, stocking principles and biosecurity measures, proper water exchange $(80 \%)$ and incorporating fermented product with commercial feed. Bondad-Reantaso et al., (2005) reported that, for better results in aquaculture, proper disease diagnosis, forecasting and planning are very essential for which knowledge about disease, its aetiology, epizootiology and diagnostic technique are compulsory. In management point of view, most of the farmers of Andhra Pradesh were following intensified culture practices and BMP for getting better results in shrimp production. Most of the farmers (especially large farmers) are following BMP during cultures such as bio-security measures of using bird (scare lines on culture pond) and crab fencing, hand dip and foot wash at entrance of the farm for people involving in culturing practice but they could not control unnecessary human interventions. In the present investigation, farmers reported that they have observed solider cap disorder earlier in $P$. monodon farming during 1990s. However, till to date there are no scientific reports on soldier cap disorder from shrimp producing countries. In the present study, only preliminary work has been done on soldier cap disorder in $P$. vannamei. Further investigations need to be done regarding aetiological agents of solider cap disorder to find out its cause.

Laboratory investigation along with epidemiological survey on 'solider cap disorder' may provide detailed information related to this disorder.

\section{Acknowledgement}

Authors are gratefully acknowledge the farmers of Nellore, Prakasham, Krishna, and West Godavari districts of Andhra Pradesh for extending their co-operation in providing information and samples of water and shrimp for this study.

\section{References}

Abraham, T.J and Samal, D. 2008. Incidence of different disease conditions in shrimp culture systems of West Bengal with special reference to white spot syndrome virus infection. Journal of the Inland Fisheries Society of India. 40(2): 1-6.

Adger W. 1998. Sustainability and social resilience in coastal resources use. In: GEC-1997-23, CSERGE working paper.

Ahmad, T., Sanyal, K.B., Mukherjee, D., Abraham, T.J and Gadadhar, D. 2017. Detection of white spot virus (WSV) in Litopenaeus vannamei from shrimp aquaculture farms in East Midnapore district, West Bengal (India). International journal of fisheries and aquatic studies. 5(2): 210-205.

Alavandi, S.V., Vijayan, K.K. and Rajendran, K.V. 1995. Shrimp diseases, their prevention and control. CIBA Bulletin. 3: 1-17.

Araneda, M., Pérez, E.P. and Gasca-Leyva, E. 2008. White shrimp Penaeus vannamei culture in freshwater at three densities: condition state based on length and weight. Aquaculture. 283(1): 13-18.

Babu, P.S., Razvi, S.S.H., Venugopal, G., Ramireddy, P., Mohan, K.M., Rao, P.S., Patnaik, R.R.S., Narasimhacharyulu, V. and Ananthan, P.S. 2014.Growth and production performance of Pacific white leg shrimp Litopenaeus vannamei (Boone, 1931) in low stocking short term farming in earthen pond conditions. Indian Journal of Fisheries. 61(4).

Bondad-Reantaso, M.G., Subasinghe, R.P, Arthur, J.R., Ogawa, K., Chinabut, S., Adlard, Tan, Z and Shariff, M. 2005. Disease and health management in Asian aquaculture. Veterinary parasitology. 32(3), pp.249-272. 
Boyd CE. 2003. Bottom soil and water quality management in shrimp ponds. Journal of Applied Aquaculture. 13(1-2), pp.1133.

FAO (Food and Agricultural Organization of United Nations). 2016. The state of world fisheries and Aquaculture, Rome. p. 29.

FAO (Food and Agriculture Organization of the United Nations), 2009. Fishmeal market report-May 2009. Food and Agriculture Organization of the United Nations-Globefish. Online: http:// www.globefish.org.

Karuppasamy, A and Mathivanan, V.2013. Comparative Growth Analysis of Litopenaeusvennamei in Different Stocking Density at Different Farms of the Kottakudi Estuary, South East Coast of India. Int. J. Fish. Aquat. Sci. 1(2): 40-44.

Kumaran, M., Anand, P.R., Kumar, J.A., Ravisankar, T., Paul, J., Vimala, D.D and Raja, KA.2017. Is Pacific white shrimp (Penaeus vannamei) farming in India is technically efficient?-A comprehensive study. Aquaculture. 468: 262-270.

Margabandu, V and Ramamurthy, D. 2015. Recent Farming Practices for Culturing Sustainable Pacific White Shrimp, Peneaus vannamei. Int. J. Sci. Res. 4(2): 9-12.

Mastan, S.A. 2015. Incidence of white feces syndrome (WFS) in farm-reared shrimp, Litopenaeus vannamei, Andhra Pradesh. Indo American Journal of Pharmaceutical Research. 5(09): 30443047.

Mude, J.N and Ravuru, D.B. 2015. Growth of cultured white Leg Shrimp Litopenaeus vannamei (Boone, 1931) of brackish water culture system in summer season with artificial diet. $J$ Aquac Res Development. 6(2): 304-305.
Murray, A.G. and Peeler, E.J. 2005. A framework for understanding the potential for emerging diseases in aquaculture. Preventive veterinary medicine. 67(2): 223-235.

Paul Raj R, Chandrapal GD, Manimaran B, Sinha MK, Vincent D, Priya G, Ramesh Kumar S. (Eds). 2010. Compendium on introduction and farming of SPF Litopenaeus vannamei in India. Coastal Aquaculture authority of India, Chennai, India, $35 \mathrm{Pp}$.

Rajendran, K.V., Shivam, S., EzhilPraveena, P., SahayaRajan, J.J., Sathish Kumar, T., Satheesha, A., Jagadeesan, V., Prasad Babu, S.V.A.N.V., Ashish, P., Navaneeth, K. A., Alavandi, S.V. Vijavan, KK. 2016. Emergence of Enterocytozoon hepatopenaei (EHP) in farmed Penaeus (Litopenaeus) vannamei in India. Aquaculture. 454: 272-280.

Santhosh kumar, S., Shivakumar, S., Vimal, S., Abdul Majeed, S., Taju, G., Haribabu, P., Uma, A and Sahul Hameed, A.S. 2016. Biochemical changes and tissue distribution of Enterocytozoon hepatopenaei (EHP) in naturally and experimentally EHPinfected white leg shrimp, Litopenaeus vannamei (Boone, 1931), in India. Journal of Fish Diseases. 40: 529-539.

Sedhuraman, V., Haq, B.M.A., Kavitha, P., Ahamed, S.A., Rao, M.V., Tiwary, C. and Srinivasan, M. 2014. Status on nonalien species SPF Pacific white shrimp Litopenaeus vannamei in India - an overview. Journal of Applied Science and Research. 2 (5):126-145.

Suresh, K., Divya V.H., Sevok, H., Sam Peter, Rakesh, C.G., Sneha, K.G., Manojkumar, D and Pillai, D. 2018b. Incidence of Hepatopancreatic Microsporidiasis, by Enterocytozoon hepatopenaei (EHP) in Penaeus vannamei Culture in Nellore District, 
Andhra Pradesh, India and the Role of Management in its Prevention and Transmission. Int.J.Curr.Microbiol. App.Sci. 7(02): 2125-2134.

Suresh, K., Srinu, R., Pillai, D and Rajesh, G. 2018a.HepatopancreaticMicrosporidiasi s (HPM) in Shrimp culture: A Review. Int.J.Curr.Microbiol.App.Sci. 7(01): 3208-3215.

Tourtip, S., Wongtripop, S., Stentiford, G.D., Bateman, K.S., Sriurairatana, S., Chavadej, J. and Withyachumnarnkul, B. 2009. Enterocytozoon hepatopenaei sp. nov. (Microsporida:
Enterocytozoonidae), a parasite of the black tiger shrimp Penaeus monodon (Decapoda: Penaeidae): Fine structure and phylogenetic relationships. Journal of invertebrate pathology. 102(1): 2129.

Wyban, J., Walsh, W.A and Godin, D.M.1995. Temperature effects on growth, feeding rate and feed conversion of the Pacific white shrimp (Penaeus vannamei). Aquaculture. 138(1): 267-279.

\section{How to cite this article:}

Suresh Kummari, Neeraja Tambireddy, B. Madhusudhan Rao, Srinu Rathlavath, Satyanarayana Boda and Lavanya Chethurajupally. 2018. A Study on Soldier Cap Disorder in Penaeus vannamei from Culture Ponds of Andhra Pradesh, India. Int.J.Curr.Microbiol.App.Sci. 7(04): 3421-3430. doi: https://doi.org/10.20546/ijcmas.2018.704.387 